Portland State University

PDXScholar

2-26-1993

\title{
The Effect of Color on Character Recognition: A Study of the Oregon License Plate
}

Frank R. Dennis

Portland State University

Follow this and additional works at: https://pdxscholar.library.pdx.edu/open_access_etds

Part of the Psychology Commons

Let us know how access to this document benefits you.

\section{Recommended Citation}

Dennis, Frank R., "The Effect of Color on Character Recognition: A Study of the Oregon License Plate" (1993). Dissertations and Theses. Paper 4576.

https://doi.org/10.15760/etd.6460

This Thesis is brought to you for free and open access. It has been accepted for inclusion in Dissertations and Theses by an authorized administrator of PDXScholar. Please contact us if we can make this document more accessible: pdxscholar@pdx.edu. 
AN ABSTRACT OF THE THESIS OF Frank R. Dennis for the Master of Science in Psychology presented February 26, 1993.

Title: The Effect of Color on Character Recognition: A Study of the Oregon License Plate

APPROVED BY THE MEMBERS OF THE THESIS COMMITTEE:

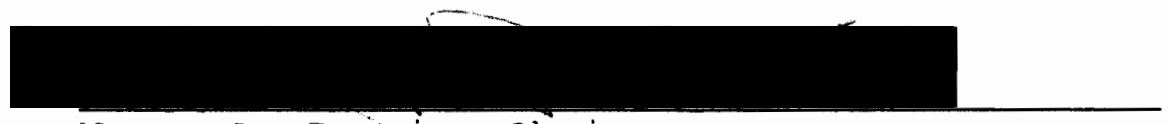

Nancy A. Peryin, Chair

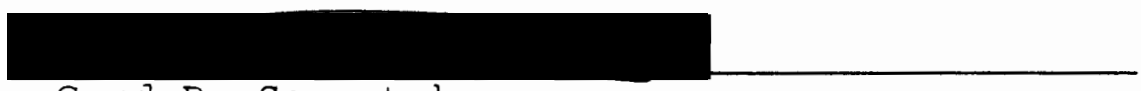

Cord B. Sengstake

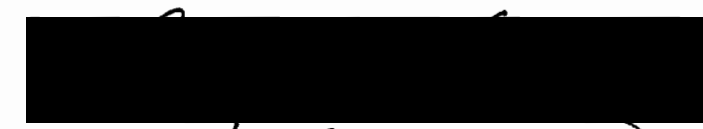

Barry F! Anderson

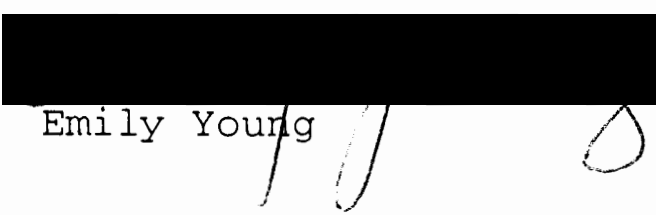

This study investigated character color changes on the current Oregon license plate in an attempt to rectify character recognition problems currently experienced with personalized license plates. Red-violet, brown, and purple were tested against the blue color currently used on the Oregon license plate's characters. Aesthetic-preference analyses were conducted to ensure that the potential character color changes maintained the appeal of the current plate. A standard recognition paradigm was used to test 
errors in letter recognition for the 4 colors.

Fifty-four subjects with normal or corrected normal

visual acuity and normal color vision were solicited from

undergraduate psychology courses. All 54 volunteers

participated in the first experiment which scaled

preferences of the four character color alternatives using

Thurstonian scaling. Fifty subjects were used in the second experiment which examined character recognition differences. The analyses focused on the center character of a 3character string positioned with the central character on the green tree.

Thurstonian scaling results indicated that the current blue character color was most preferred and brown was least preferred. ANOVA results found significant differences in character recognition between the four colors. The current blue color yielded the best character recognition, followed by red violet, purple and then brown. The findings were not congruent with Indow's (1988) study suggesting colors further removed from green on the color cognitive map should produce superior character recognition. A theoretical explanation of the results indicating that brightness differences, not hue, may have led to blue's superior performance is discussed. 
THE EFFECT OF COLOR ON CHARACTER RECOGNITION:

A STUDY OF THE OREGON LICENSE PLATE

by

FRANK R. DENNIS

A thesis submitted in partial fulfillment of the requirements for the degree of

MASTER OF SCIENCE

in

PSYCHOLOGY

Portland State University

1993 
TO THE OFFICE OF GRADUATE STUDIES:

The members of the Committee approve the thesis of Frank R. Dennis presented February 26, 1993.
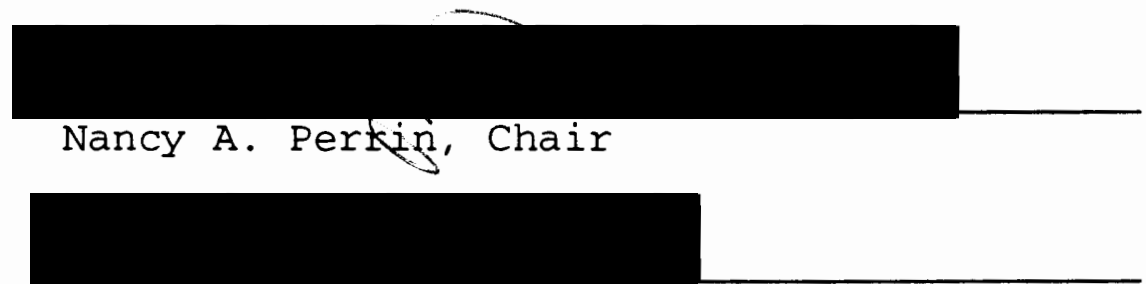

Cord B. Sengstake

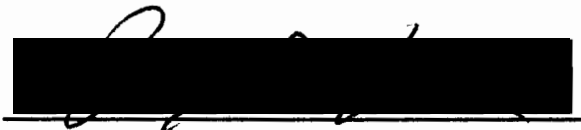

Barry $F$. Anderson

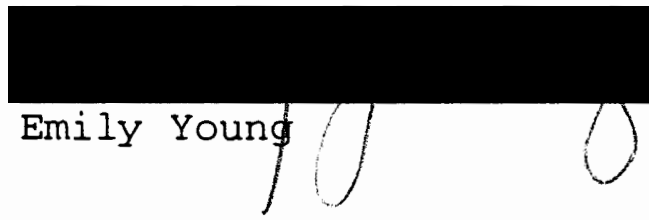

APPROVED :

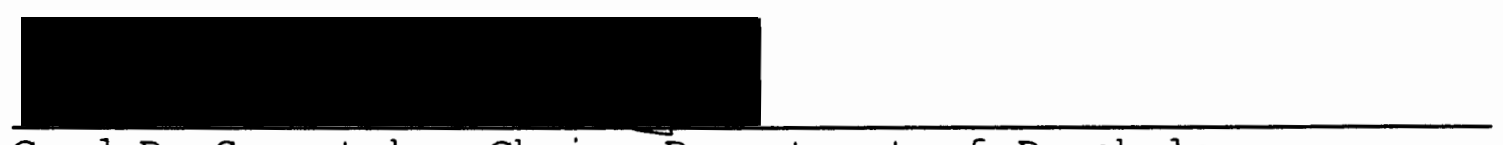

Cord B. Sengstake, Chair, Department of Psychology

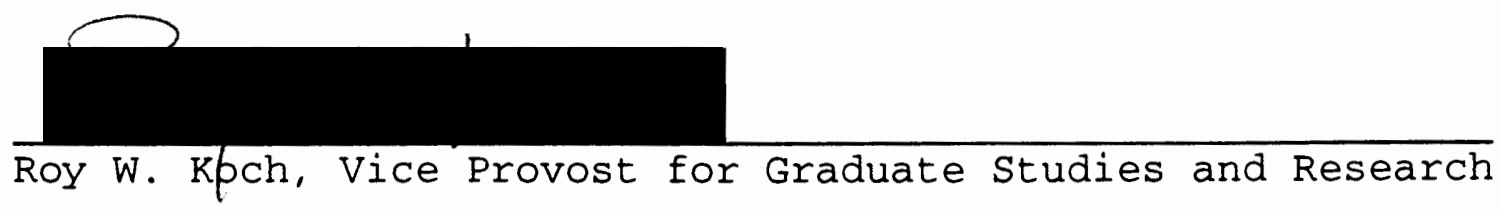




\section{DEDICATION}

This thesis is dedicated to Erika Dennis, whose pride in me has always been a source of motivation; and Donna Dennis, whose love and support has enabled this endeavor to be far less arduous. 
TABLE OF CONTENTS

PAGE

LIST OF TABLES $\ldots \ldots \ldots \ldots \ldots \ldots \ldots \ldots \ldots \ldots \ldots \ldots \ldots \ldots \ldots \ldots \ldots$

LIST OF FIGURES .......................... vii

INTRODUCTION . . . . . . . . . . . . . . .

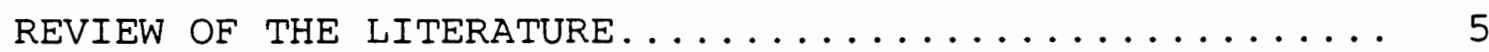

Letter recognition and recall............ 6

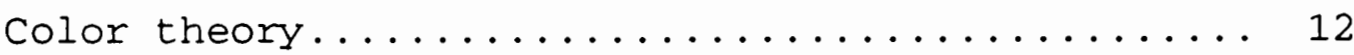

DESCRIPTION OF THE PROBLEM................ 18

The Oregon license plate............... 18

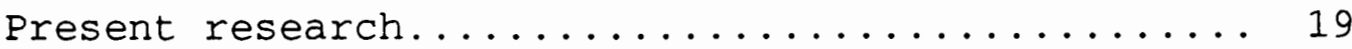

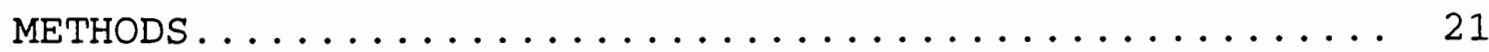

Subjects....................... 21

Stimulus materials.................. 22

Experimental set-up.................. 23

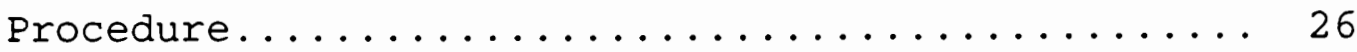

Experiment 1

Experiment 2

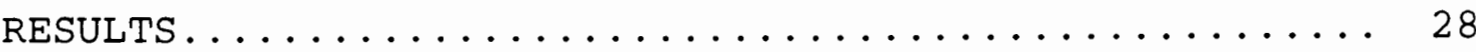

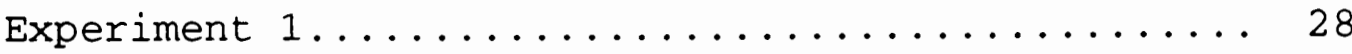

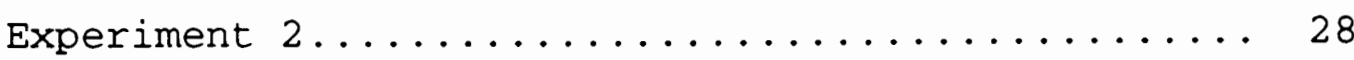

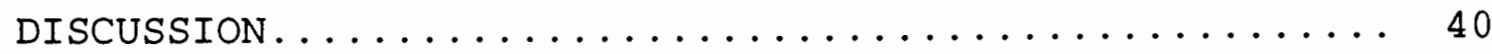

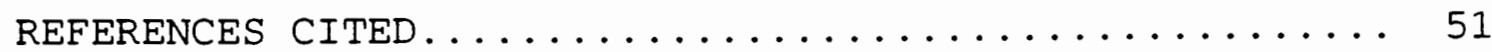


APPENDICES

A $\quad 3 M$ LICENSE PLATE LETTER COLORS............ 56

B $\quad$ STACK ELEMENTS.................. 58

C INFORMED CONSENT ................... 61

D STACK PRESENTATION ORDERS ............. 63 


\section{LIST OF TABLES}

TABLE

PAGE

I Preference data matrix: number of times row preferred over column............. 29

II ANOVA on proportional errors: order stack I

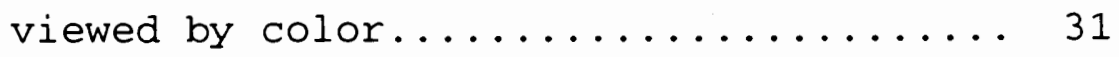

III ANOVA on proportional errors: order stack II

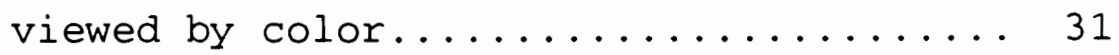

IV ANOVA on proportional errors: order stack III

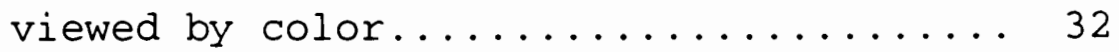

V ANOVA on proportional errors: order stack IV viewed by color................... 32

VI Proportional error means (\& standard deviations) across orders: stack I..... 34

VII Proportional error means (\& standard deviations) across orders: stack II.... 34

VIII Proportional error means (\& standard

deviations) across orders: stack III.... 35

IX Proportional error means (\& standard

deviations) across orders: stack IV.... 35

X ANOVA on proportional errors: stack by color 36

XI Proportional error means (\& standard

deviations) across stacks.......... 38 
XII ANOVA on middle character: number of errors

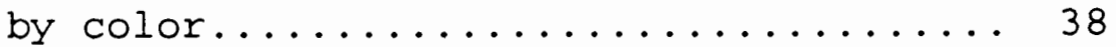




\section{LIST OF FIGURES}

F IGURE

PAGE

1. The Oregon 1 icense plate............... 3

2. The simplified color solid.............. 13

3. Indow's (1988) color cognitive map......... 17

4. Diagram of experimental set-up........... 25 


\section{INTRODUCTION}

Graphic art has been following an interesting new trend in our society. Artists have left the conventional canvas and for some time have been promoting commercial products as well as art on tee-shirts, billboards, ballcaps, and a variety of other unusual surfaces. These surfaces function as "miniature billboards" with people carrying advertising messages on and with them while conducting their daily Iives.

In a sense, various state motor-vehicle divisions have been involved in "advertising" practices since the issue of graphically illustrated license plates. These plates now serve the dual function of providing automobile ownership/ registration information while simultaneously presenting illustrations of favorite state themes, images, or values residents supposedly enjoy. Unfortunately, graphic plates are not always designed with optimal character recognition in mind. The graphics can make the license plates difficult to read. These difficulties can arise because of forms (e.g., trees, mountains) placed on the plate and/or colors which are difficult to distinguish. The goal of this study was to investigate the effect of color on character readability using a Iicense plate with a complex graphic image and to test the aesthetic appeal of these varying 
colors on the graphic license plate.

The number of states adopting graphic license plates is growing. In 1981, eighteen states had license plates that incorporated a graphic image; in 1992 the number increased to 40 (Polks, 1992; Federal Highway Administration, 1981). There are several possible explanations for the popularity of graphic license plates. They could represent the states' desire to be seen as progressive, or may represent the hope of greater tourism attraction, and perhaps more business dollars entering the represented state. At the very least, the plate attracts greater attention. Oregon joined the ranks of states providing graphic plates with the 1987 introduction of a statewide contest soliciting public design ideas for the license plate. The Oregon Department of Transportation selected an eight-member panel to judge 8,555 plate entries, weeding out entries that were judged to be redundant, weak, or otherwise not conforming with contest rules (Federman 1988; Rollins, 1987, 1988). The eightmember panel consisted of students, artists, two representatives from law enforcement agencies, and a state senator. Five entries were selected and were sent to the Oregon Department of Transportation where the final winning entry was chosen.

Figure 1 presents the winning graphic. The plate featured a brown fir tree silhouetted by lavender and purple mountains against a peach colored sky. The tree color was 


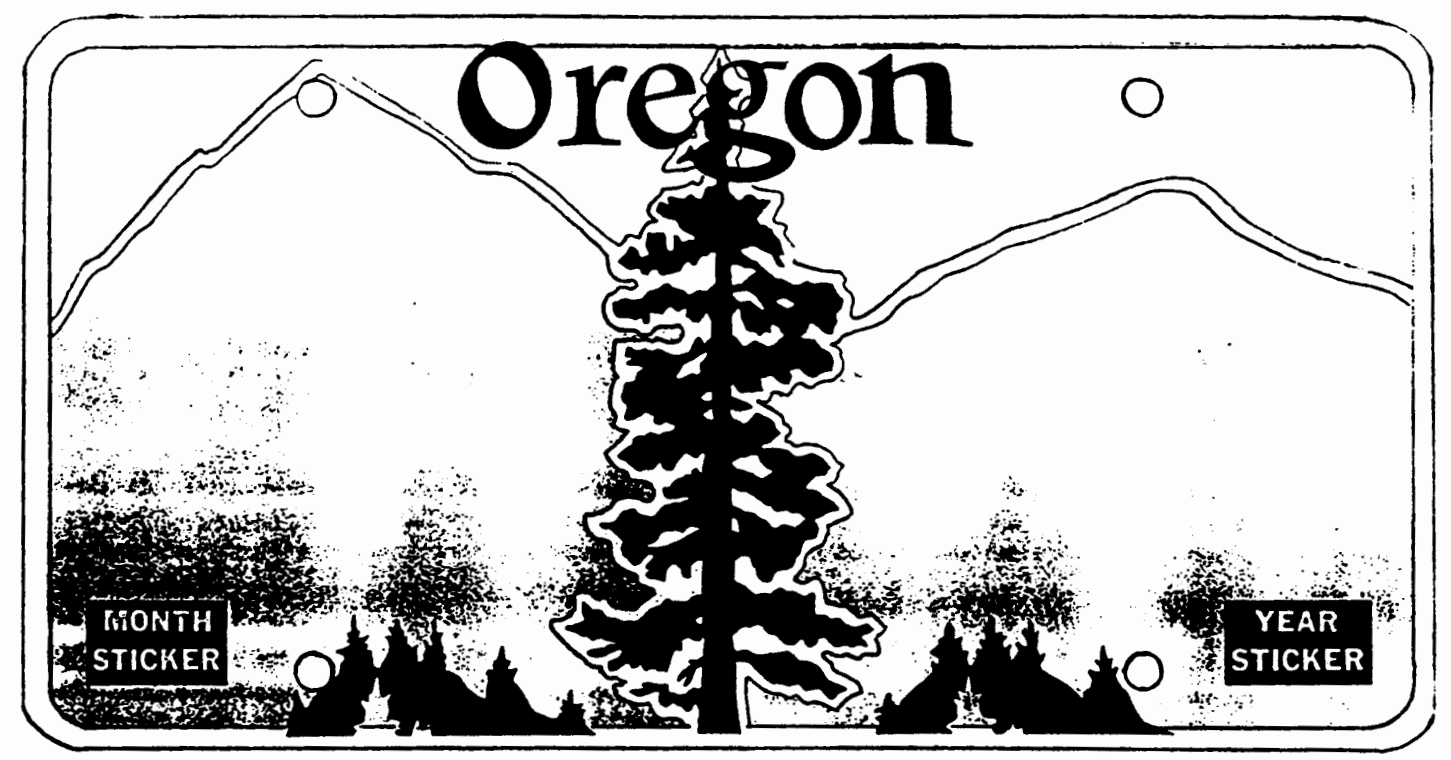

Fiqure 1. The Oregon license plate. 
unpopular with citizens, however. They complained that the tree appeared "dead" and so the tree's color was changed to light green (Federman, 1988; Rollins, 1988). The plate was then officially issued, and soon after the colors were changed again -- this time because although the design was liked, it appeared "washed out" in sun and headlights (Smith, 1988). The third and final recoloring changed the tree from a "20\% to $70 \%$ " green, the mountains from a "10\% to $40 \% "$ purple, and the sky from peach to light blue (Goetze, 1989). The changes did improve the plate's graphics, but failed to satisfy law enforcement officials' wishes that the tree color should not interfere with the reading of the plate's characters (Federman, 1988). It is interesting to note that no research on the readability of the license plates was conducted as part of the selection process. The present study addressed this issue by examining character recognition on the Oregon license plate and the effect of changing the color of the characters. Other states have potentially similar problems with graphic license plate designs, therefore the experimental paradigm and results of this study could be useful for other states. 


\section{REVIEW OF THE LITERATURE}

Color is not the only variable effecting the readability of license plates. Certain characters tend to be more easily confused with certain other characters (Estes, 1972; Gibson, 1969; Mackinnon, O'Reilly, and Geiselman, 1990; Mende, Mackinnon, and Geiselman, 1987; McIntyre, Fox, and Neale, 1970). It is reasonable to assume that poor weather conditions may intensify discrimination problems. We have all noticed the after-market customized license plate covers, frames, lights, or other vehicle modifications can hinder a license plate's readability. Limited exposure time to the license plate, which may occur if an automobile is speeding away, can effect character recognition (Mende et al., 1987). Further, physiological conditions such as arousal seem likely to effect character discrimination on licence plates.

Unfortunately, no studies exist that focus on graphic license plate character discrimination problems. However, considerable research addresses similar character or "target" recognition issues that are relevant to license plate character discrimination. These studies have identified that factors such as character string length and stimulus exposure time, redundancy effects, pattern recognition, color, and color contrast can influence 
character recognition. These findings can be generalized to license plate character recognition.

\section{LETTER RECOGNITION AND RECALL}

Estes (1978), Macworth (1963), Mende, Mackinnon, and Geiselman (1987), and Miller (1972) noted the effects of length of character strings and length of exposure to stimuli (character strings) on recall. In general, it was found that the longer the character string, the greater chance for error, and the longer the exposure time to a stimulus, the greater the chance of correct recollection. Intuitively, these findings can be generalized to license plates. The first finding suggests that as the number of letters and numbers on a license plate increase, correct recall is likely to decrease. In addition, considering that a person attending to a license plate may have limited exposure to the plate and therefore limited time to encode the characters, (particularly if the automobile is accelerating away), exposure time becomes an important variable for the good character recognition that is necessary for accurate recall.

Three theories dominate the literature on character recognition: template theory, prototype matching, and feature detection theory. Numerous studies have been conducted on character recognition and confusion errors in an effort to support these theories. 
Template theory (Anderson, 1990; Eysenck, 1984, Matlin, 1988, 1989) hypothesizes that any perceived character is represented by an exact one-to-one model of it in the mind. Thus, recognition of letters is based on a perceived character being compared with stored "templates" until a match is obtained resulting in recognition. Arguments against the theory state that it is inadequate because it lacks flexibility (Eysenck, 1984; Matlin, 1988, 1989). That is, templates are required to make perfect matches to perceived stimuli in form, color, size, position, and degree of completeness (such as a typewritten "A" missing part of the horizontal line, etc.). Unless an exact match is made, no recognition will occur. This requires an infinite number of templates to be stored in order to accommodate the infinite number of possible variations for a single character. The theory has an additional shortcoming in that it fails to explain character confusions.

Prototype matching (Eysenck, 1984; Matlin, 1988, 1989; Posner, Goldsmith, \& Welton, 1967) provides flexibility in pattern or letter recognition that template theory lacks. This theory states that models of stimuli are stored, and that incoming stimuli are compared less rigidly against those models. Dember and Warm (1979) and Klatzky (1975) illustrate the theory by describing the recognition of an airplane. Seeing different variations of a prototypic large tubular structure with wings does not prevent recognition of 
the object as an airplane, just as seeing different variations of a letter does not prevent it's identification. However, although prototype matching theory has flexibility that allows a more conservative approach to memory storage, the theory lacks physiological evidence defining how the system operates (Matlin, 1988, 1989). Further, similar to template matching, prototype matching fails to explain common character confusions.

Feature detection theory is touted to be both flexible and possessing physiological evidence for its existence (Anderson, 1990; Dember and Warner, 1979; Matlin, 1988, 1989; Walley and Weiden, 1973). Feature detection theory states that patterns are recognized by means of the distinctive features that comprise them. In the case of letters, roundness, horizontal and vertical lines are examples of the elements essential in letter recognition (Anderson, 1990; Gibson, 1969; Matlin, 1988, 1989). Thus, two letters that have common distinctive features are thought to be more frequently confused with each other than with other letters not sharing those features. The distinctive feature paradigm has been frequently used in letter recognition research (Estes, 1972; Garner, 1988 ; Holbrook, 1975; Kunnapas, 1966; McIntyre, Fox, and Neale, 1970; Miller, 1972; Mackinnon, O'Reilly, and Geiselman, 1990; Pick and Unze, 1979; Walley and Weiden, 1973). In fact, Holbrook (1975) and Kunnapas (1966) note the relation 
between character recognition errors based on similarity and brief exposure time discussed earlier.

Although feature detection theory seems to be the model of choice in current character recognition studies, some investigators resist defining feature detection as totally unique from template and prototype theories. Dember and Warm (1979) argue that distinctive feature detection is probably only part of a more complex system since recognition occurs in instances where features may be only partially present (such as an incomplete "A"). Other investigators point out that specific features in and of themselves can be plausibly viewed as mini-templates, or that feature detection models may be more appropriately viewed as complex prototypical models. For example, feature detection theories involve recognizing specific parts of a stimulus, but those parts' relationship to one another must be integrated into a whole, or single (prototypic) unit (Eysenck, 1984; Caldwell and Hall, 1970; Matlin, 1989).

There are aspects of character recognition that are not fully explained by any of these theories. For example, character recognition can be enhanced in certain situations, even with incomplete letters (e.g. lacking all or part of distinctive features). When letters are presented in the context of a word they are more easily identified than when presented in the form of nonsense words (Chastain, 1981, 1986; Soloman, May, and Schwartz, 1981; Wheeler, 1970). 
Additionally, certain combinations of characters that are not word structured seem to facilitate character recognition and discrimination. Redundancies of certain letters grouped together facilitate recognition. For example, McIntyre, et al. (1970) found that when noise letters in an array consisted of only "O" (versus random letters), correct recognition of target letters " $T$ " and "F" were significantly increased. The same study also found that when target and redundant noise letters increased in similarity (based on distinctive features), redundancy effects decreased. In a later study, Estes (1972) varied the number of redundant noise characters presented with a target letter. His results revealed lower error rates in target letter recognition as the number of redundant noise characters were increased.

Interestingly, however, when target letters are flanked by themselves recognition can be inhibited (Bjork and Murray, 1977; Egeth and Santee, 1981; Eriksen and Eriksen, 1979), although contrary evidence of this inhibitory effect exists as well. Eriksen and Lappin (1965); Taylor, (1977) and Keele (1969) found facilitation effects with same target/ noise letters. This contradiction has been suggested to be occurring at different levels of processing (Egeth and Santee, 1981). For example, inhibition may be due to lateral processes at a physiological level relative to the proximity of neurons used in feature detection. Neurons excited by certain stimulus orientations may inhibit 
the excitation of other similar neurons the closer they lie together in the cortex. Conversely, the errors may be related to similar fatigue of neurons utilized in the semantic level of information processing. Keele (1969) explained the facilitation effect. He noted that facilitation in character recognition may be due to subjects raising their expectancy of seeing a target letter after seeing it as a background letter.

Similar to Bjork and Murray (1977), Estes (1972), and McIntyre, et al. (1970), and closer to the focus of this study, was Neisser's (1963) findings on target/background affects. He found that discrimination increases as targets become more distinct from their background. For example, angular target letters in a context of curved letters are more easily recognized than in a background of other angular letters. This finding is of central concern in this study since the Oregon plate can be represented as having "target" characters against a background graphic. Another way to give a target the ability to "stand out" is to color the target [character] differently from the background (Garner, 1988; Spiker, Rogers, and Cicinelli, 1986; Pick and Unze, 1986). Previous research on color may provide useful information on color and related contrast effects to optimize character discrimination from background graphics. 
COLOR THEORY

Color is commonly defined by the physical components that constitute light. Hue, or color, is the psychological reaction to the different wavelengths of light from $400 \mathrm{~nm}$ (perceived violet) to $700 \mathrm{~nm}$ (perceived red). Saturation (chroma) is the result of the purity of the wavelengths; brightness is the psychological representation of intensity. The components of light are commonly integrated into models illustrating human color perception. Based on these components, the Munsell color solid is widely used as a model or schematic in the sciences and art (Matlin, 1988; Mueller and Rudolph, 1966), and has been suggested as a logical basis for a model of human color perception or cognitive mapping (Indow, 1988). Figure 2 presents Matlin's (1988) simplified example of the Munsell color solid.

The Munsell color solid illustrates color perception three-dimensionally by first bending the color spectrum into a near-circle. A gap exists between the red and violet spectral ends, filled in by non-spectral hues formed by combining the end spectral hues (for example blue and red, yielding purple). Thus, the circumference consists of monochromatic hues, those produced by a single wavelength, and the joining non-spectral combinations between red and violet. The resulting circular diagram is commonly known as the "color wheel". Saturation diminishes as a progression is made from the fully saturated circumference along the 


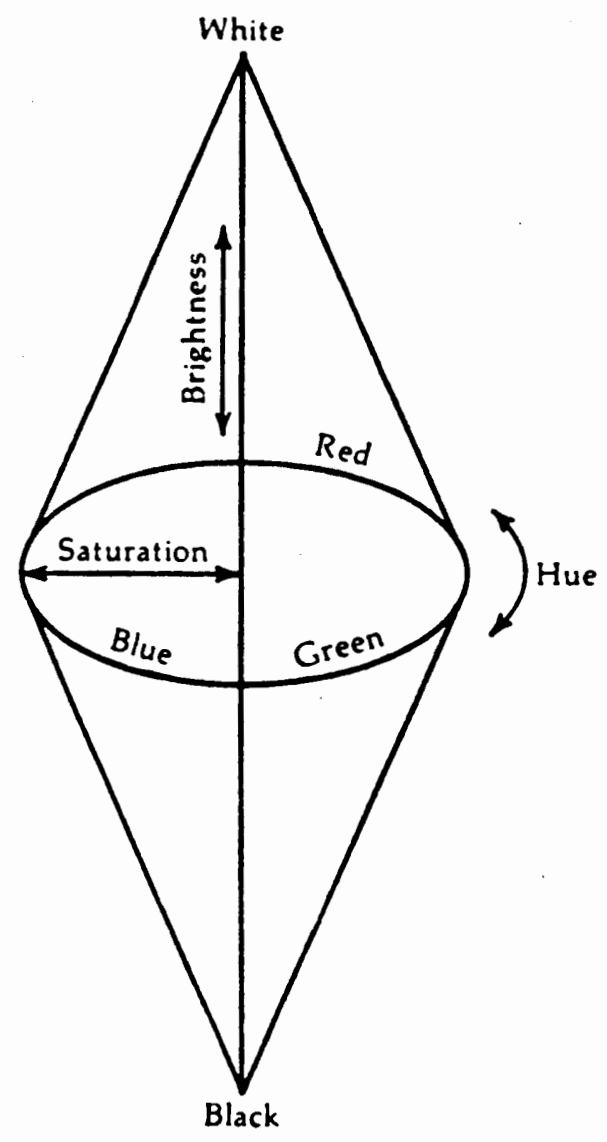

Figure 2. The simplified color solid. (Matlin, 1988; pp. 110.) 
hue's radius toward the vertical axis, or center of the wheel. Brightness is represented by a vector perpendicular to the color wheel at the axis. Colors above the plane of the color wheel contain increasing amounts of white; below the color wheel plane, increasing amounts of black. The color solid models the additive properties of color in light. For example, colored lights, represented by points on the color solid, can be added to produce any other color found on the solid. Further, the solid models the metameric properties of light; an infinite number variations of colored lights on the solid can be added to produce any particular color on the solid (Indow, 1988; Matlin, 1988; Mueller and Rudolph, 1966). Pigment colors are also represented on the color solid, although the properties of their combinations are different and are not modeled on the color solid. Since pigment colors absorb certain light wavelengths, reflecting those not absorbed, surface colors utilize subtractive properties of mixing instead of the additive properties represented on the color solid (Matlin, 1988; Mueller, 1966). Thus, the addition of a red light and a green light of equal intensity would yield a yellow color, red and green pigments mixed would yield a darkish color; the former mixture would be modeled on the color solid, the latter would not.

Color contrast studies have yielded interesting effects when colors are positioned next to or within one another. 
Adjacent colors may produce contrast effects enhancing distinction of one another at the region of their border, i.e., the Mach effect, (Hurvich, 1981). The most dramatic Mach effects have been defined in achromatic colors (Cornsweet, 1970; Hurvich, 1981). Hurvich (1981) notes that Mach effects in chromatic colors have been proposed but are not yet widely accepted.

Viewing two adjacent colors may create perceived simultaneous contrast effects causing perceived hue to be different from the hue when viewed alone. Complementary hues (colors on the color solid that when added produce gray) induce their complement on achromatic surfaces (Beck, 1972; Cornsweet, 1970; Hurvich, 1981; Matlin, 1988; Spiker, Rogers, and Cicinelli, 1986), and even on other chromatic surfaces (Cornsweet, 1970; Hurvich, 1981; Matlin, 1988; Spiker, et al., 1986). Color CRT users notice the effect when grey letters or symbols are displayed on a yellow screen; the symbols take on a blue tint. The effect also can be noted by placing a blue colored card next to a grey card; the grey card will exhibit a yellow tint, particularly along the line where they meet. Further, colors surrounded by lighter colors are perceived to be darker, and vice versa (Hurvich, 1981; Spiker, et al., 1986).

Color discrimination studies may yield insight into target and background color selections leading to better character discrimination. Matlin (1988) notes the 
difficulty in color distinction when hues varied from "true" colors in adjacent colors (ie. blue and green) in the spectrum. (True colors are defined as those that elicit agreement in naming the colors, and are seldom confused.) She described the effect specifically in the blue to green region, but noted the effect has been demonstrated in other adjacent colors as well. Additionally, Indow's (1988) research in color cognitive mapping revealed asymmetry in the blue and green region: blue and green seemed perceptually closer than other adjacent spectral colors. He suggested that colors further apart on the cognitive map may be easier to distinguish. The closer proximity of blue and green than that of other hues may be further evidence of the difficulty in these color's distinction to which Matlin (1988) referred. Figure 3 presents Indow's (1988) cognitive map for color recognition. 


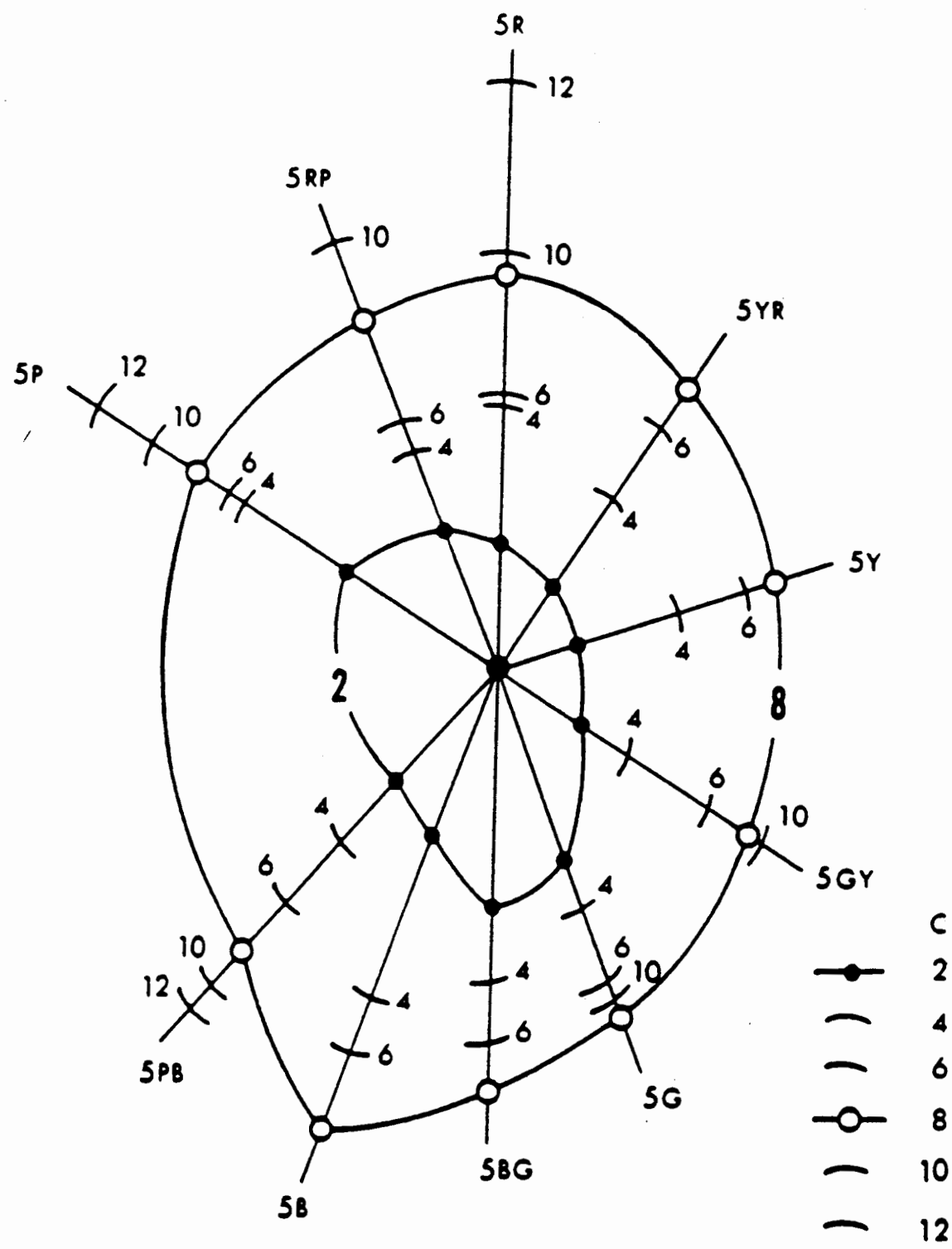

Eigure 3. Indow's (1988) color cognitive map. Figure shown lies in plane of constant brightness. Perceptual irregularities are modeled by hue angles and irregular saturation (C) circumference lines; pp.463. 


\section{DESCRIPTION OF THE PROBLEM}

\section{THE OREGON LICENSE PLATE}

The current Oregon license plate graphic consists of a dark green tree centered on the plate and between two lavender mountains, trimmed with a small line of dark blue mountains and trees on the lower edge of the plate. The plate's letters and numbers are also painted dark blue. On many personalized license plates, the blue characters lie wholely or partially on the green tree, (some personalized plates' characters avoid the tree). The previously mentioned color phenomena may lead to color discrimination difficulty and increased character recognition problems for the Oregon license plate when the characters lie on the tree. The previously mentioned contrast effects of character colors on adjacent plate background colors may act to "blur" lines, edges, and shapes of characters necessary for recognition. The problems may be all the more intensified with personalized Oregon license plates due to the use of blue characters that cross the green tree, as evidenced by Matlin (1988) and Indow's (1988) findings. 


\section{PRESENT RESEARCH}

The goal of the present study was to find a possible character color alternative that would result in superior character recognition of letters placed on the green tree when compared to the current Oregon license plate. Further, the character color was sought with an attempt to retain at least the aesthetic appeal of the current plate. Four colors were tested that were the actual hues available from the $3 \mathrm{M}$ Company, the manufacturer of the paint used on the license plates' characters.

To accomplish this goal, two experiments were conducted. Experiment 1 investigated the aesthetic appeal of 4 sample license plates using actual-size reproductions that varied only in letter color. Experiment 2 was a letter recognition experiment designed to investigate the effect of varying character color on the oregon license plate. The Oregon Department of Motor Vehicles (DMV) suggested that this was the only viable change to the license plate since the green tree had already been varied three times and the final graphic scene is well liked (B. Jones, personal conversation, November 15, 1991).

In the aesthetic experiment, subjects were presented pairs of license plates with three characters on either side of the tree. The subjects were then asked to indicate the plate they found more aesthetically appealing.

In the recognition experiment, license plates were 
composed of three letters with the middle character centered on the tree. Only highly confusable letters were used since it has been found that numbers are not confused in the same manner as letters (Fryklund, 1975). In addition, DMV data revealed that only one-third of personalized license plates contain numeric characters (B. Jones, personal conversation, December 23, 1991). 


\section{METHODS}

\section{SUBJECTS}

Fifty-four volunteer subjects were recruited from introductory or other undergraduate psychology classes. The sample included 35 females and 19 males. Subjects were asked to participate on a volunteer basis and advised that good visual acuity and normal color vision were required. Subjects received extra credit points for their involvement from their instructor.

Prior to beginning the experimental trials, subjects were asked to fill out consent forms and then screened to assess their color vision using the Ishihara Test for Color Vision (Schiffman, 1990). Students' visual acuity was screened by their answer to the question, "Do you have normal or corrected normal vision?" All 54 subjects passed the Ishihara screening tests and were used in Experiment 1 of the study. However, the data from four subjects $(\# 2,3$, 26, and 52) were not used in the analysis of Experiment 2 (recognition). One subject was excluded due to visual acuity problems, and the other three subjects were excluded because of recording equipment malfunctions. The four subject exclusions resulted in a gender mix of 33 females and 17 males for Experiment 2 . 


\section{STIMULUS MATERIALS}

License plate replications were created using actual 6 in. $\mathrm{x} 12$ in. unstamped license plates provided by the oregon Department of Motor Vehicles and colored, adhesive-backed, reflective paper provided by the $3 \mathrm{M}$ Corporation. The material obtained from $3 \mathrm{M}$ matched four of the paint colors currently used in the roll-paint process to paint stamped characters on license plates (see Appendix A). The colors tested were Blue Velvet, $4808 \mathrm{~V}$ (referred to throughout this study as blue); Brown, 4816V; Purple, 4815V; and Violet, 4801V. (Violet was referred to as red $\mathrm{v}$. in this study since Red $4802 \mathrm{~V}$ was not used, but the rollcoat color $4801 \mathrm{~V}$ appears reddish in color). Two of the four character colors, red v. and purple, were chosen via an informal survey of an undergraduate psychology class accessing which of the 12 "Rollcoat 4800 series" colors would be most appealing as a replacement to the current blue character color. DMV suggested brown, and the final color used was the plates' current blue. Characters were cut from the colored reflective material using photo-copied charactertemplates created from actual license plates.

Four license plates were created for Experiment 1 using each of the 4 colors. The characters "ABC 000 " were centered on either side of the license plates' green tree.

For Experiment 2, 50 character strings were selected, and 4 plates were made using each string but varying the 
color. Therefore 200 stimulus plates were created. Each character string contained only three letters to reduce potential negative effects of string length on recognition (Miller, 1972). Stimulus materials were prepared from the following 10 letters, found by Gibson (1969) to be easily confused because of shared distinctive features: A, F, E, $H, I, T, L, P, R$, and $B$. Of the 720 possible 3-letter sequences that could be formed from these letters, 50 were generated randomly without replacement with the restrictions that (a) each letter be in the center position of five strings and (b) no string spell a word. These 50 3-letter sequences were then repeated to form 4 sets which differed only in that the 4 colors, red $v .$, blue, brown, and purple, were randomly assigned without replacement to the 4 repetitions of each 3 -letter sequence across sets, (see Appendix B). All 4 sets were presented, in a different random order, to each subject.

\section{EXPERIMENTAL SET-UP}

No special apparatus was required for the aesthetic experiment, however, the recognition experiment required subjects to be seated at a distance away from the license plates where character recognition problems were noticed. One factor in defining this distance was that actual license plates have stamped characters. Three-dimensional letters may aid in character recognition at close distances (Fisher, 
1978). This factor was addressed by simulating perception at distances where contours perceptually dissolve. A distance of about 40 feet, slightly less than that of the width of a 2-lane intersection, produced the desired effect. Since the room used to conduct the experiment was not 40 feet long, this distance was created using two mirrors positioned so that the subject viewed the license plates through a double reflection (see Figure 4 ). The subjects looked forward at a mirror $16 \mathrm{ft}$ away from them. This mirror was positioned to reflect an image from a second mirror $20.16 \mathrm{ft}$ from the first mirror. The second mirror was angled to project the image of the plate from the presentation podium. The distance between the second mirror and the spot the actual plate was displayed was $6 \mathrm{ft}$. The presentation podium was positioned at approximately subject eye level. This set-up produced the $40 \mathrm{ft}$ distance between the subject and the license plate subtending a visual angle of 1.146 degrees $\times 2.292$ degrees.

Stimulus exposure time was $.50 \mathrm{sec}$ and regulated by a computer running a cadence program that signaled the investigator to show the plate, followed by a signal to flip the plate down and out of subjects' view. The computer prompt was carefully situated out of subjects' view. The room lights were turned off for Experiment 2 and the plates were illuminated by a single 75 watt light positioned to eliminate glare.' Responses were recorded in this experiment 


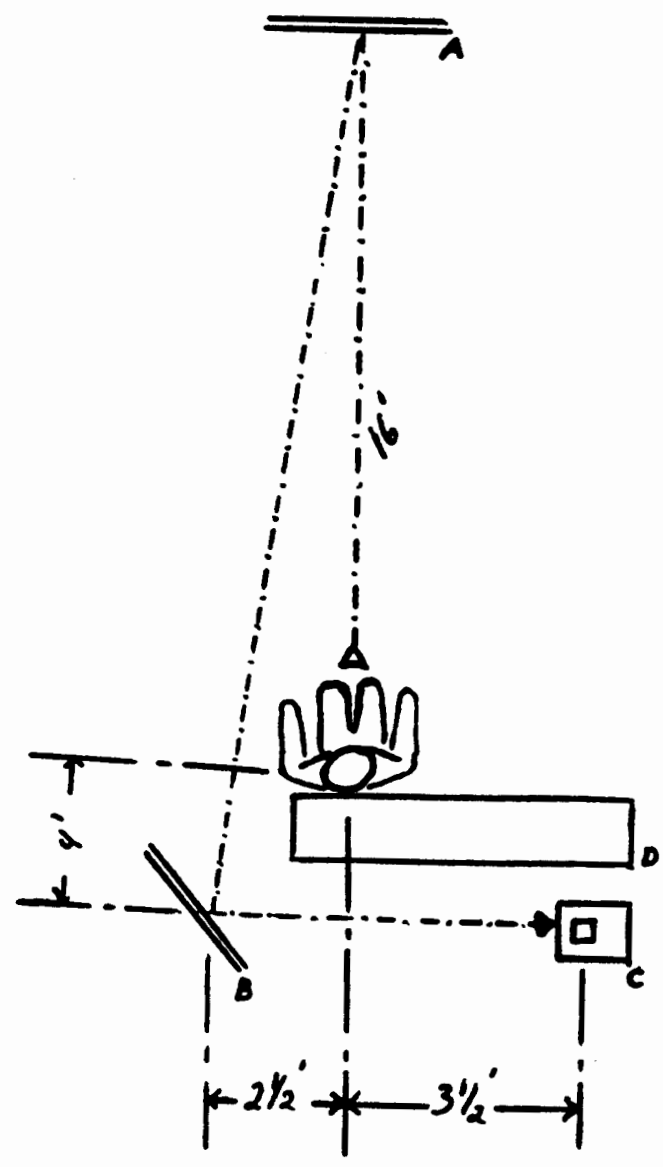

Figure 4. Diagram of experimental set-up. Subject views front mirror (A) reflecting plate podium (C) through second mirror (B); partition (D) separates subject from stimuli. 
via a tape recorder and later transcribed by the experimenter.

\section{PROCEDURE}

Subjects were first given consent forms which outlined the experiment, their participation, and their recourse should they experience any discomfort as a result of their participation (see Appendix C). Subjects were encouraged to ask questions at any time during the study.

\section{Experiment 1}

After the experimenter received the signed consent form, it was explained again that the study was an investigation of alternatives to the current license plate. Subjects were told that two license plates would be presented together and that they would be asked to verbally indicate their aesthetic preference. All 6 pairs of the 4 character colors were presented in random order, varying which pairs were presented first, second, etc., to control for order effects. Subjects looked down at the plates displayed flat on a table at a distance of about $3 \mathrm{ft}$. and were allowed to view the pairs as closely and as long as they wanted. Subject's preferences were recorded by the experimenter. Comments relevant to the study were noted. 


\section{Experiment 2}

The 200 plates were randomized for presentation in each of four stacks of 50. Each stack contained 50 unique character strings which varied in color and order. The plates with identical 3 -letter strings differing only in color were randomly assigned one to each of the four stacks ensuring that each character string appeared only once in each stack. Next, the plates within each stack were randomly ordered. (Appendix B lists each stack and its elements.) Thus, the order character strings appeared within each stack was the same for all subjects, however the presentation order of the four stacks was randomly selected for each subject.

A brief discussion explaining the character discrimination problem to subjects preceded the onset of experimental trials. Students were told that the study was an attempt to determine alternative character colors that may lead to better discrimination on the Oregon license plate.

The experimental trials began with the experimenter asking if the subject was ready. Upon an affirmative response, the first stack of plates was presented one at a time. A brief rest period was offered between the second and third stacks. Subjects were debriefed, and comments relevant to the study were noted. 


\section{RESULTS}

\section{EXPERIMENT 1}

Table I presents the preference data matrix. Entries represent the number of times the row was preferred over the column. Thurstonian scaling was used to analyze the preference data. The current blue character color was preferred over the other three colors. Blue had the highest scaled preference value of 1.923, followed by purple, 1.648; red V., 1.425; and then brown, 0 . Since these numbers are on an interval scale, it can be seen that blue was .275 more preferred than purple; purple was preferred .223 more than red V., and red V. was preferred 1.425 over brown.

\section{EXPERIMENT 2}

During the randomization process, the four stacks were not balanced with regard to the number of times each color appeared in the stacks; for example, one stack may have contained more blue plates than another, less red v., etc., (see Appendix B). Also, the order each stack was seen was randomly assigned for each subject; therefore the stacks were not seen by an equal number of subjects in each order (see Appendix D.) Because of these imbalances two sets of ANOVAs were required to test for order effects. Since 
TABLE I

PREFERENCE DATA MATRIX: NUMBER

OF TIMES ROW PREFERRED

OVER COLUMN

Red v. Blue Brown Purple

Red $v$.

18

49

23

Blue

36

53

31

Brown

5

1

3

Purple

31

23

51 
multiple analyses were conducted, alpha was set at .01 rather than the more traditional .05. The first set of 2way mixed ANOVAs determined whether the order in which the four stacks of stimuli were shown affected error rates. The second repeated-measures ANOVA accessed whether the error rates of the stacks themselves were different. These analyses were done on the middle character errors only.

The first set of four 2-way mixed ANOVAs examined the effect of the order in which the stack was presented and the effect of color on errors for each stack. For example, the first ANOVA looked at stack I only and compared errors when that stack was seen 1st, 2nd, 3rd, and 4 th for the four colors. These analyses were conducted to check for a learning effect. If such an effect occurred, the later a stack was seen, the lower the error rate should be. Color was included as an independent variable in these analyses to test if a found learning effect was the same for all colors. For these analyses, error rates were converted to proportional errors. The number of errors noted for each color in each stack was divided by the number of times each color appeared. This was required since the four stacks were not equal in the number of times that each color appeared in each stack. ANOVA results are presented in Tables II-V.

The analysis revealed no significant interaction effects between order and color for any stack. With the 
TABLE II

ANOVA ON PROPORTIONAL ERRORS:

ORDER STACK I VIEWED

BY COLOR

Order

\begin{tabular}{rrrrr} 
df & \multicolumn{1}{c}{ SS } & MS & $F$ & D>F \\
3 & 215.19 & 71.73 & 4.47 & 0.0077 \\
46 & 737.86 & 16.04 & & \\
3 & 238.93 & 79.64 & 57.57 & 0.0001 \\
9 & 23.28 & 2.59 & 1.87 & 0.6140 \\
138 & 190.91 & 1.31 & &
\end{tabular}

Error (within)

Error (between)

color

Order $\mathrm{x}$ Color

138

190.91

\section{TABLE III}

ANOVA ON PROPORTIONAL ERRORS:

ORDER STACK II VIEWED

BY COLOR

Order

Error (between)

Color

Order x Color

Error (within)
SS

$$
42.26
$$

14.09

0.79

0.5071

46

822.90

17.89

3

241.08

80.36

53.44

0.0001

9

2.18

0.24

0.16

0.9973

138

207.52

1.50 
TABLE IV

ANOVA ON PROPORTIONAL ERRORS:

ORDER STACK III VIEWED

BY COLOR

\begin{tabular}{lrrrrr} 
& df & SS & MS & F & D>F \\
\cline { 2 - 6 } Order & 3 & 74.99 & 24.99 & 1.77 & 0.3308 \\
Error (between) & 46 & 981.30 & 21.33 & & \\
Color & 3 & 26.99 & 8.99 & 7.95 & 0.0001 \\
Order x Color & 9 & 9.42 & 1.05 & 0.92 & 0.5259 \\
Error (within) & 138 & 156.14 & 1.13 & &
\end{tabular}

TABLE V

ANOVA ON PROPORTIONAL ERRORS:

ORDER STACK IV VIEWED

BY COLOR

\begin{tabular}{rrrrr} 
df & SS & MS & F & P $>F$ \\
\hline 3 & 37.66 & 12.55 & 0.66 & 0.5787 \\
46 & 870.39 & 18.92 & & \\
3 & 11.88 & 3.96 & 2.49 & 0.0629 \\
9 & 13.60 & 1.51 & 0.95 & 0.4826 \\
138 & 219.11 & 1.59 & &
\end{tabular}

Order

Error (between)

Color

Order $x$ Color

Error (within)

138

219.11 
exception of stack I, the order each stack was presented made no significant difference in errors. Significant color differences were found for all stacks except in stack IV.

The above analyses suggested that a learning effect did not exist for any color, with the exception of stack I. For this stack error rates differed across the 4 orders but the pattern was the same for all colors. The reason why stack I results were not congruent with the other stacks is not clear. Perhaps stack I was more difficult than the other stacks, and since there was more room for improvement an effect was detected. The second ANOVA examines the relative difficulty of the stacks. The data were collapsed across orders to test if the error rates are significantly different for the four stacks. Stack I-IV proportional error means, number of times each color appeared in each stack, and number of times each stack was presented in each order are depicted in Tables VI-IX, ( $N$ = number of subjects, $P=$ number of plates represented of relative color per stack).

In the second analysis, a single repeated-measures ANOVA examined differences between stacks I-IV and color and the stack $x$ color interaction. The ANOVA on the collapsed data is presented in Table $\mathrm{X}$.

There was a significant stack $\mathrm{x}$ color interaction. This finding suggests that errors for the stacks are not the same for any one color, understandable given that the 


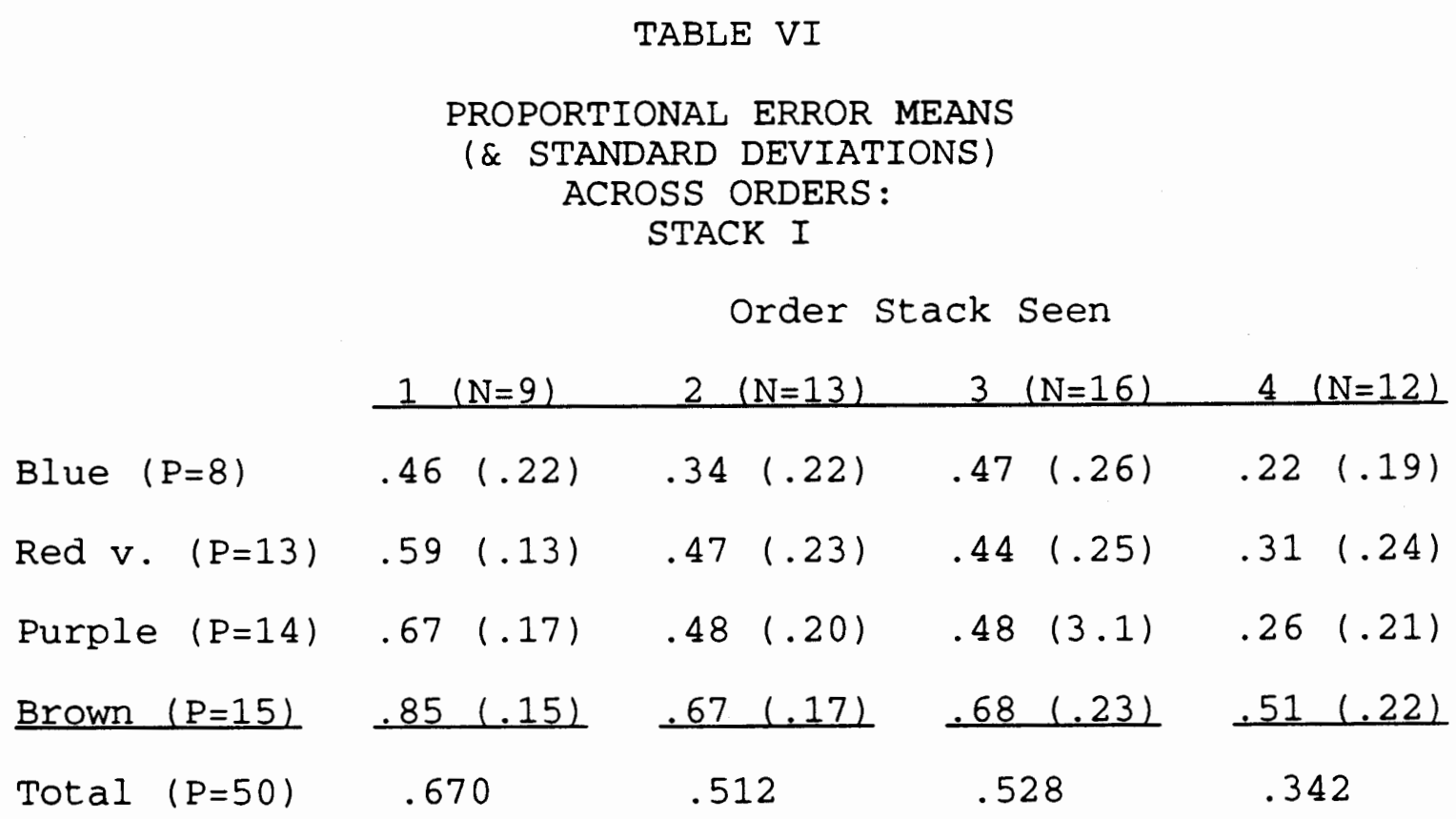

TABLE VII

PROPORTIONAL ERROR MEANS

(\& STANDARD DEVIATIONS)

ACROSS ORDERS :

STACK II

Order Stack Seen

$1(N=17) \quad 2(N=14) \quad 3(N=10) \quad 4 \quad(N=9)$

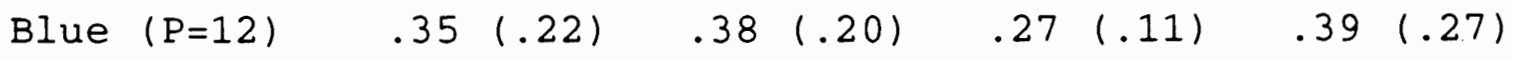

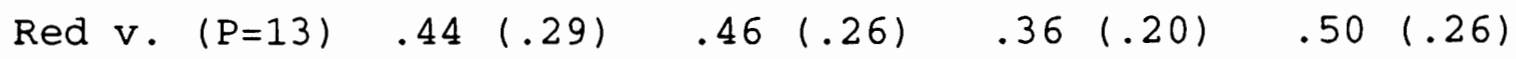

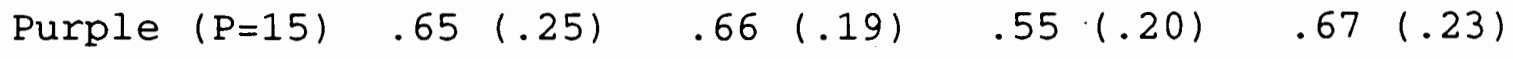

Brown $(P=10) \quad .59(.22) \quad .59(.26) \quad .45(.30) \quad .58(.26)$

$\begin{array}{llll}\text { Total }(\mathrm{P}=50) & .511 & .527 & .413\end{array}$ 


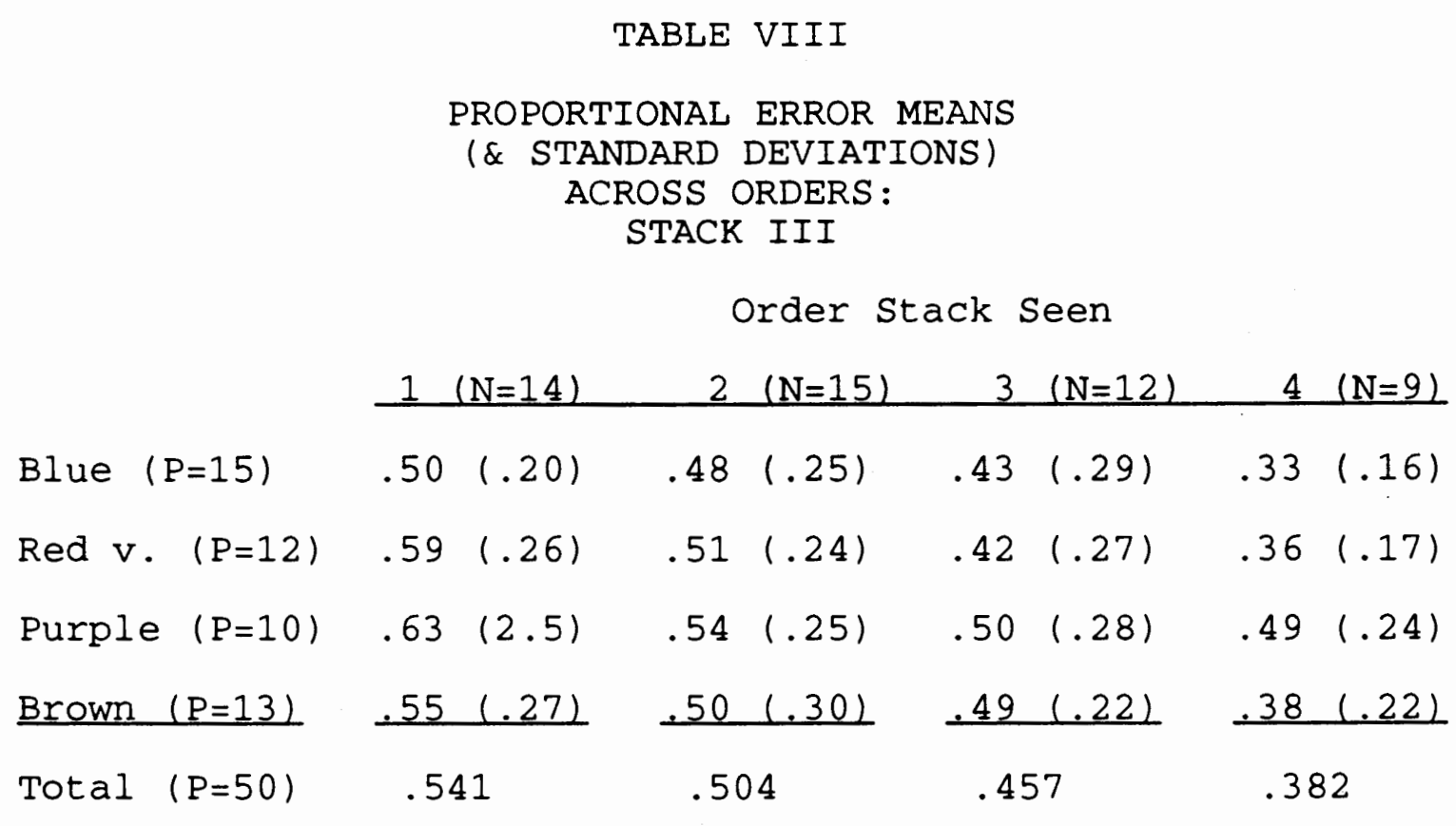

TABLE IX

PROPORTIONAL ERROR MEANS

(\& STANDARD DEVIATIONS)

ACROSS ORDERS:

STACK IV

Order Stack Seen

$1(\mathrm{~N}=10) \quad 2(\mathrm{~N}=8) \quad 3(\mathrm{~N}=12) \quad 4(\mathrm{~N}=20)$

$\begin{array}{lllllllll}\text { Blue } & (P=15) \quad .52 & (.23) & .48 & (.21) & .39 & (.13) & .46 & (.24)\end{array}$

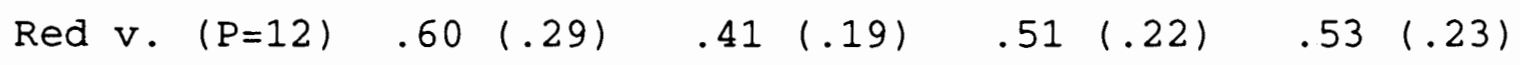

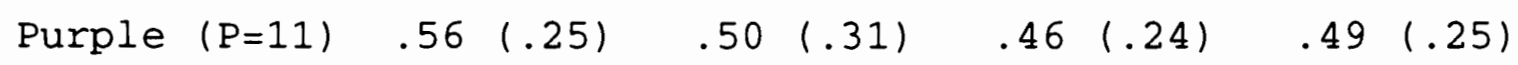

Brown (P=12) $.63(.28) \quad .45(.27) \quad .49(.26) \quad .50 \quad(.27)$

$\begin{array}{lllll}\text { Total }(\mathrm{P}=50) & .574 & .460 & .458 & .493\end{array}$ 
TABLE $X$

ANOVA ON PROPORTIONAL ERRORS: STACK BY COLOR

\begin{tabular}{lrrrrr} 
& df & SS & MS & $F$ & P F \\
\cline { 2 - 6 } Stack & 3 & 1.85 & 0.62 & 0.20 & 0.8967 \\
Error (Stack) & 147 & 454.69 & 3.09 & & \\
Color & 3 & 1127.80 & 375.93 & 65.92 & 0.0001 \\
Error (Color) & 147 & 838.38 & 5.70 & & \\
Stack x Color & 9 & 236.93 & 26.33 & 18.95 & 0.0001 \\
Error (Stack x Color) & 441 & 612.56 & 1.39 & &
\end{tabular}


specific plates in each stack vary across stacks for any one color (see Appendix B). In Appendix B, note that each stack contained the same letters but varied in the color of these letters. Some letters could be especially difficult to read when placed on the green tree. Therefore the stack $\mathrm{x}$ color effect may reflect these difficulties (or letter effect) rather than a different color effect for each stack. When the data are collapsed across color, (stack main effect in the ANOVA) errors are the same for all four stacks as are the letters. Table XI presents the proportional means for each color in each stack, and the total proportional errors collapsed over color. Additionally, Appendix B shows that the letters which appear in each stack are the same for the four stacks. Further, as expected the 4 colors produced significant differences in errors.

Lack of consistent order and significant stack differences in the two previous analyses concluded that learning effects were not found. Therefore, it was decided to collapse the data across stacks. In the final analysis, the number of errors were added across the 4 stacks for each color. A one-way repeated measures ANOVA on the actual number of errors for the middle character was computed. Significant error differences were found for the four colors, as presented in Table XII.

Mean number of errors for each of the colors were blue, $20.68(s d=9.76)$; red v., 23.58 ( $s d=10.94)$; purple, 


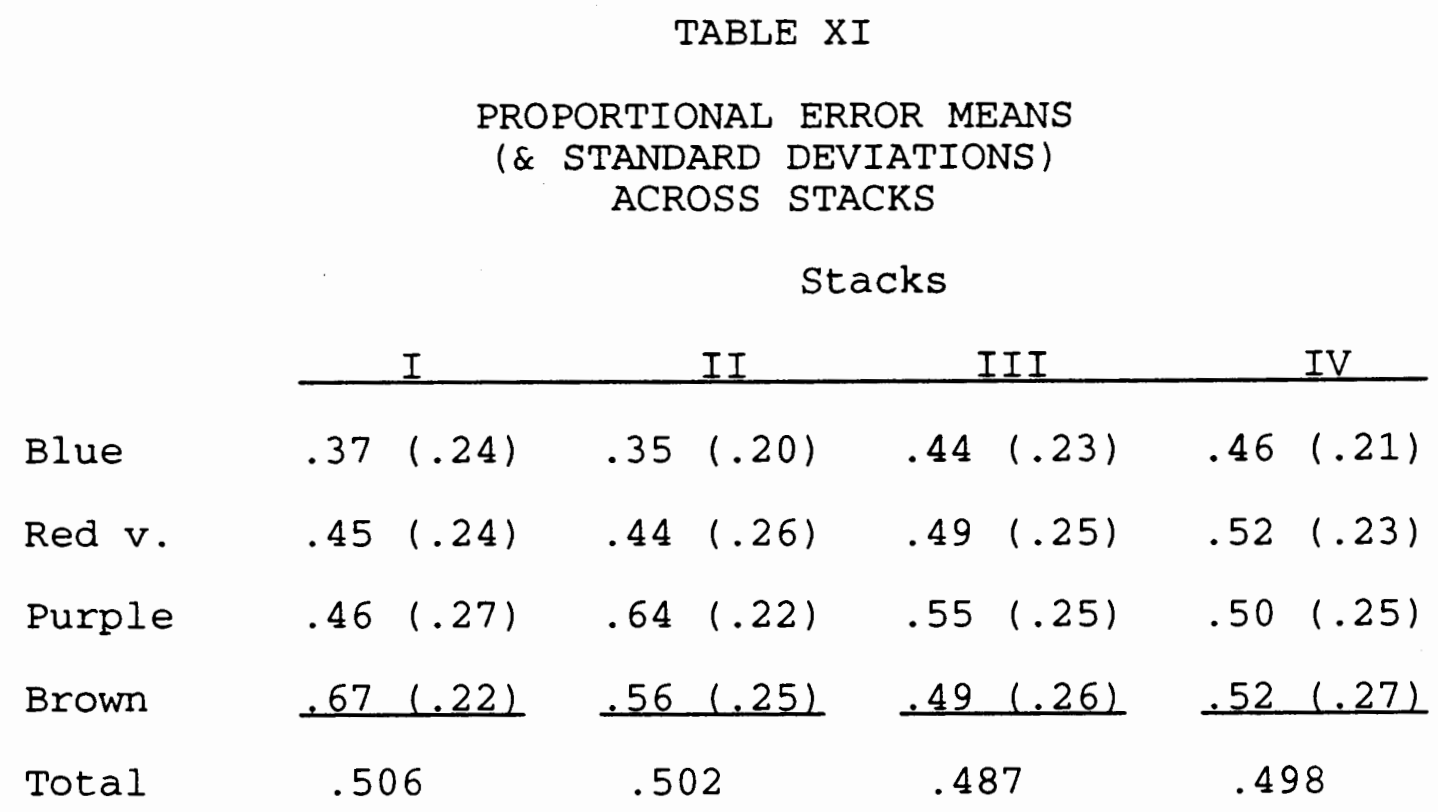

TABLE XII

ANOVA ON MIDDLE CHARACTER:

NUMBER OF ERRORS

BY COLOR

\begin{tabular}{lllll}
$d f$ & $S S$ & $M S$ & $F$ & $P>F$ \\
\hline
\end{tabular}

Color

$\begin{array}{lllll}3 & 1716.28 & 572.09 & 63.58 & 0.0001\end{array}$

Error (Color)

$147 \quad 1322.72$

9.00 
$26.94(s d=10.88) ;$ and brown, $28.16(s d=10.73)$. Recall that each color was seen 50 times by each subject. Using planned contrasts the red V., purple, and brown colors were compared against the current blue. All three colors had significantly higher error rates than the current blue plate, (red V., $F=18.89$; purple, $F=107.68$; brown, $F=111.40$; $d f=1,49, p=0.0001$ for all comparisons). Thus, the analysis showed that blue had the best recognition performance.

One-way repeated measures ANOVAs of number of errors on left and right characters by color were conducted as well. No significant differences in errors between colors were revealed for either the left or right character. Mean number of errors for the left character were blue, 1.44 $(s d=2.21)$; red V., 1.82 ( $s d=2.80)$; purple, 1.82 (sd=2.99); and brown, $2.06(\mathrm{sd}=2.98)$. Mean number of errors for the right character were blue, $0.82(s d=1.56)$; red $v ., 0.86$ $(s d=1.90)$; purple, $0.92(s d=1.47)$; and brown, 0.90 (sd=1.97). Therefore the analysis showed that color did not effect the recognition performance for letters that are not placed on the green tree of the oregon license plate. 


\section{DISCUSSION}

Experiment 1 found that the current blue character color was preferred over the other three colors tested. Purple, red $\mathrm{V} .$, and then brown followed in preference; however purple and red $\mathrm{v}$. were very close to blue in scale value compared to brown. Thus, the findings reveal that brown was the most strongly disfavored color tested, and would probably cause the greatest citizen disapproval if it was selected as a replacement color on the current oregon Iicense plate.

Insight into the reason for blue's preference and brown's rejection may lie in the subjects' reactions during the Experiment 1 trials. Preference responses for colors were notably quicker when the pair included the brown plate. Further, the Iicense plates with brown characters elicited several responses such as, "That color is ugly." Perhaps blue was favored due to a sort of a 'familiarity' effect; subjects may be more comfortable with what they have come to know. Or, perhaps the subjects simply liked the blue color and disliked the brown. Similar experiments should be conducted on future license plates prior to issue if aesthetics are a high priority. Results should vary with different graphic designs.

It is important to keep in mind that while most states 
favor license plate design changes for aesthetic reasons, changes in license plate designs must retain good character recognition. Experiment 2 was designed to increase the readability of an existing license plate with a graphic design that is already well liked, but interferes with character recognition.

Two sets of ANOVAs examined color, stack, order, and interaction effects since color was not balanced across stacks and stacks were not balanced across presentation order. The ultimate goal was to find that ordering had no effect on error (learning effect) and that stack errors could be added in the final analysis. The analysis revealed that the order in which stacks II-IV were presented made no significant difference in errors. The order that stack I was seen, however, did produce a significant effect. Proportional error means suggest a decline in magnitude, similar to a learning effect.

The reason a learning effect was noted in stack I, and not in the other three, is not clear. One possible explanation may lie in the construct of the individual stacks. Color was not balanced across the stacks, so stacks varied in the number of plates with each color. Stack I had 15 license plates with brown characters; more brown characters than any other stack. Looking forward at the final analysis for a moment, brown also produced more errors than any of the other three colors tested $(28.16$ mean errors 
out of 50 possible). Perhaps because stack I contained the greatest number of the most problematic color made stack I more difficult than the other three. This may have resulted in stack I being difficult enough to produce a learning effect as there is more room for improvement, whereas the other three stacks did not.

The second explanation may be that stack I showed an order effect simply due to chance. No clear systematic evidence was found for learning effect since no effect was found in stacks II through IV. If a significant learning effect were present in the experiment, it is reasonable to assume that it would turn up in the other stacks as well.

Lack of a systematic order effect facilitated collapsing across orders for a stack $x$ color analysis. The results again revealed expected color differences. No significant differences were noted between stacks. (This appears to contradict the greater difficulty of stack I as an explanation for the learning effect offered in the preceding paragraphs. However, when errors are collapsed over the four orders, brown's influence on stack I may have been washed out.)

The second analysis revealed a stack $x$ color interaction. This finding suggests that the pattern of errors for each color is not the same for each stack. Table XI illustrates this effect. Previous studies and Appendix B may shed some light on this. Neisser (1963) noted that 
targets that share similar features with background items are more difficult to detect. It can be argued that some of the letter's features noted by Gibson (1969) are similar to features that comprise the Oregon license plate's green tree. For example, letters $\mathrm{L}, \mathrm{H}, \mathrm{E}$, and $\mathrm{P}$ appeared to be more difficult to recognize in the data. If the argument is accepted, letters that share greater amounts of those features would be more difficult to recognize than others with less, when positioned on the tree. Additionally, each character string is represented by each color only once. Difficult character and difficult color combinations may exhibit an adverse synergic effect on character recognition. Recall that color was not balanced across stacks, and that certain stacks had more of some colors than others (see Appendix B). Therefore, the possibility exists that some stacks contained difficult character/ difficult color combinations that others may not have. Some stacks may have contained a greater number of "easier" colors on the difficult characters, and some stacks may have had more characters colored with a difficult color. Further evidence for this difficult character/ difficult color explanation is suggested by the lack of a main effect for stack. When color is ignored, all stacks contain identical characters, and no error differences are noted.

It was concluded that there were no systematic order and stack effects, therefore the data for each color was 
collapsed across the four stacks. The color analysis, conducted on actual errors instead of proportions, revealed that significant error differences exist between the four character colors. Surprisingly, blue characters were found to produce the best recognition when placed on the green tree. This result is not what was predicted by earlier research. Evidence presented by Matlin (1988) suggested that any of the other three (non-adjacent spectral) character colors would produce superior character recognition. Adjacent spectral colors are commonly confused and blue is adjacent to green on the color spectrum. Similarly, Indow's (1988) cognitive mapping study suggested any of the other colors would produce better recognition. Red and purple oppose green on the cognitive map and are therefore perceptually furthest away, and thus were expected to render the best character recognition (see Figure 3 ).

Previous studies may give insight into why the present study failed to find a different color that produced superior recognition on the Oregon license plate. Studies by Fryklund (1975), and Farmer and Taylor (1980), state that quick target recognition is dependent on the target standing out from it's background. Giampaolo, Maloney, Fekete, and Al-Basi (1989) recognized that targets are composed of a mosaic of features, and that all that is required for quick recognition is that at least one feature that comprises it be unique from the background. They stated that these 
features all have their own feature maps similar to that of Indow's (1988) color cognitive map. The investigators further stated that, if features are not sufficiently distinguishable unique from the background, the subject is required to make a deliberate, attentive search for the stimuli. This attentive search requires more time, and is likely to produce more errors.

Using the above framework, the Oregon license plate can be seen to be thought of as containing three distinct features, each possessing its own feature map: color, shape, and saturation/ brightness. Color may have failed to produce acceptable letter distinction due to the distance from which the plates were viewed. Previous investigators have noted that increased distance from a target, resulting in a reduced target size, hinders discrimination of its color (Hunt, 1979). Sgt. Juilfs of the Multnomah County Sheriff's office, noted a similar problem that seems to validate this color/ distance perception problem. Oregon uses different colors for the yearly expiration stickers found in the corner of Oregon license plates. Different colors are used to enable law enforcement officers to recognize expired license plate from a distance without having to actually read the sticker's print. At a distance officers have difficulty distinguishing between some of the colors (M. Juilfs, personal conversation, October 31, 1991). Empirical evidence seems to substantiate Officer Juilfs' 
observations and elaborates further that, as the distance from a target increases, targets that differ from their background primarily in color lose their distinction from the background (Emmerson and Ross, 1986). Therefore, it appears that when a target (i.e. license plate character) is moved further away from an observer, the feature map that distinguishes color probably can no longer function in target recognition from it's background (i.e. background graphic). In the present study, if the license plates were presented at a closer distance, color may have yielded results closer to what was anticipated.

Additionally, in the present study character shapes were of no use to facilitate recognition. Neisser (1963) and Fryklund (1975) noted that when target shapes differ from their background, recognition is enhanced. Looking at the Oregon license plate an observer notes that the tree is comprised of many curved, vertical, and even horizontal lines (Figure 1). Integrating Gibson (1969), Giampaolo et al. (1989), and Neisser's (1963) findings, both target characters and the background tree share common features that may have yielded their shapes indistinguishable; therefore the "shape" feature map would be of little use in character recognition. This is evidenced by the high mean error rate produced by all 4 colors. A possible test of this hypothesis could be conducted by duplicating the present experiment, but substituting a green circle for the 
green tree. Better recognition performance of the letters would validate the hypothesis. However, the color effect would likely be similar to the present findings due to the color/ distance effect mentioned earlier.

In this discussion saturation and brightness are combined as a single variable. The combination is justified for three reasons. First, it can be argued that the tested colors all appeared to be equally saturated, so the saturation variable itself is not manipulated. All the colors tested were deep colors. Second, although saturation is not manipulated directly in this study, Matlin's (1988) simplified figure of the Munsell color solid reveals an inseparable relationship between brightness and saturation on any particular deeply saturated hue. The model requires that altering the brightness of saturated hues lying on the circumference of the color wheel requires a slight variation in saturation (Figure 2). And finally, Emmerson and Ross (1986) found evidence for separation of color and brightness, but not brightness and saturation. However, Burns and Shepp (1988) and Jameson and Hurvich (1989) question that the three elements of color can be separately distinguished.

Evidence exists suggesting that manipulating brightness holds the greatest hope for solving Oregon's current character recognition problem. This evidence favoring brightness comes from experience with the first Oregon 
graphic license plate, previous empirical studies and this investigation's results. First, early renditions of the Oregon graphic plate, exhibited background colors that were all lighter than the current plate (Goetze, 1989). It was not until the background graphic was darkened that the present character recognition problems began (M. Juilfs, personal conversation, october 31, 1991). This problem was anticipated and warned against by law enforcement officers early in the plate's design (Federman, 1988). Thus, earlier plates with lighter backgrounds were easier to read across the entire character string than the current, darker plate. Secondly, previous findings revealed that manipulating brightness as a dependent variable facilitated target recognition. Farmer and Taylor (1980) manipulated brightness as a dependent variable alone and found superior target distinction. Emmerson and Ross (1986) further noted that changes in brightness can lead to better target distinction over distance, and that changing brightness had more effect on target recognition than color.

Finally, the present study found the greatest character recognition problems lie in the green tree which was darkened most from the plate's original design. The tree was darkened from "20 percent to 70 percent" whereas the mountains were darkened only from " 10 percent to 40 percent," (Goetze, 1989). In the present study, right and left characters revealed color differences that were 
insignificant. Also, the mean number of right and left letter errors are markedly lower compared to center-letter errors. Thus, it appears that the degree to which the background was darkened may have had an effect on the degree of errors produced.

The finding that blue characters are significantly better recognized may not be a function of it's hue, but rather it's brightness. The blue color is extremely dark; dark enough that several subjects in the study referred to it as black. This hypothesis seems to be borne out by the other three color error means all being significantly higher than blue. Further, dark blue's superior recognition performance seems to be congruent with previous studies stating that brightness, and not hue, elicits better performance in difficult target/background situations. In the present study, the blue character color differed from the green tree most in brightness, not color.

Interestingly, the results at first do not seem to be congruent when brown's performance is considered. Brown is located below the color wheel plane on the Munsell color solid as is black. Brown, however produced significantly higher error rates than (the almost black) blue. Two possible explanations exist for brown not showing better performance, or at least closer to blue. First, subjects did not seem to consider brown in this study very dark. No reference was ever made to the brown being dark such as 
"the dark brown color", etc., as was common with blue. Secondly, although both blue and brown are further down on the brightness scale, brightness is likely to follow similar perception irregularities as Indow (1988) documented for both hue and saturation (Figure 3 ). It is therefore conceivable that brown simply did not fall below a distinction threshold that would have engendered it with the same superior recognition had by blue.

These results suggest the that the solution to Oregon's present character recognition problem may lie in experimenting with variations of the green tree's brightness. The present study may present a model to investigate changes in brightness while simultaneously attending to aesthetics on the oregon license plate. The study may also present a method to explore potential problems on any state's license plate before changes are issued. 


\section{REFERENCES CITED}

Anderson, J. R. (1990). Cognitive psycholooy and its implications (3rd ed.). New York: W H Freeman

Beck, J. (1972), surface color perception. Ithaca: Cornell University Press.

Bjork, E. L., \& Murray, J. T. (1977). On the nature of input channels in visual processing. Psychological Review, 84, (5), 472-484.

Burns, B., \& Shepp, B. E. (1988). Dimensional interactions and the structure of psychological space: The representation of hue, saturation, and brightness. Perception and Psychophysics, 43, (5), 494-507.

Caldwell, E. C., \& Hall, V. C. (1970). Distinctivefeatures versus prototype learning reexamined. Journal of Experimental Psychology, 83, (1), 7-12.

Chastain, G. (1986). Word-to-letter inhibition: Word inferiority and other interference effects. Memory and Cognition, 14, (4), 361-368.

Chastain, G. (1981). Phonological and orthographic factors in the word superiority effect. Memory and Cognition, 9, (4), 389-397.

Cornsweet, T. N. (1970). Visual perception. New York: Academic Press.

Dember, W. N., \& Warm, J. S. (1979). Psycholoay of perception. New York: Holf, Reinhart, \& Winston.

Egeth, H. E., \& Santee, J. L. (1981). Conceptual and perceptual components of interletter inhibition. Journal of Experimental Psychology, 2, (3), 506-517.

Emmerson, P. G., \& Ross, H. E. (1986). The effect of brightness on colour recognition under water. Ergonomics, 29, (12), 1647-1658.

Eriksen, C. W., \& Eriksen, B. A. (1979). Target redundancy in visual search: Do repetitions of the target within the display impair processing? Perception and Psychophysics, 26, (3), 195-205. 
Eriksen, C. W. \& Lappin, J. S. (1965). Internal perceptual system noise redundancy in simultaneous inputs in form identification. Psychonomic Science, $\underline{2},(12), 351-352$.

Estes, W. K. (1972). Interactions of signal and background variables in visual processing. Perception and Psychophysics, 12, (3), 278-286.

Estes, W. K. (1978). Handbook of learning and cognitive processes. Human information processing (Vol 5). Hillsdale: Lawrence Erlbaum Associates.

Eysenck, M. W. (1984). A handbook of cognitive psychology. Hillsdale: Lawrence Erlbaum Associates.

Farmer, E. W., \& Taylor, R. M. (1980). Visual search through color displays: Effects of target-background similarity and background uniformity. Perception and Psychophysics, 27, (3), 267-272.

Fisher, V. L. (1978). Letter discrimination as a function of culture, orthography and dimensionality of letters. Perceptual and Motor Skills, 46, (2), 459-464.

Federal Highway Administration. (1981). License plates 1981. (U.S. DOT Publication No. LP-I01). Washington DC: U.S. Government Printing office.

Federman, S. (1988, April 20). License plate's dead tree comes to life. The oregonian, $p$. B3.

Fryklund, I. (1975). Effects of cued-set spatial arrangement and target-background similarity in the partial-report paradigm. Perception and Psychophysics, $17,(4), 375-386$.

Giampaolo, M., Maloney, K. P., Fekete, E. M. \& Al-Basi, K. (1989). Visual search along the colour dimension. Canadian Journal of Psycholooy, 43, (1), 1-12.

Garner, W. R. (1988). Facilitation and interference with a separable redundant dimension in stimulus comparison. Perception and Psychophysics, 44, (4), 321-330.

Gibson, E. J. (1969). Principles of perceptual learning and development. New York: Appleton-Century-Crofts.

Goetze, J. (1989, October 11). Oregon plates are getting brighter. The Oregonian, p. B6. 
Holbrook, M. B. (1975). A comparison of methods for measuring the interletter similarity between capital characters. Perception and Psychophysics, 17, (6), 532536 .

Hunt, R. W. G. (1979). Search and the human observer. J. N. Claire \& M. A. Sinclair (Ed.), Colour Vision (pp. 132-140). London: Taylor and Francis.

Hurvich, L. M. (1981). Color vision. Sunderland, MA: Sinauer Associates.

Indow, T. (1988). Multidimensional studies of Munsell color solid. Psychological Review, 95, (4), 456-470.

Jameson, D., \& Hurvich, L. M. (1989). Essay concerning color constancy. Annual Review of Psychology, 40, 122 .

Keele, S. W. (1969). Repetition effect: A memory dependent process. Journal of Experimental Psychology, 80, 243-248.

Klatzky, R. L. (1975). Human memory: Structures and processes. San Francisco: W. H. Freeman.

Kunnapas, T. (1966). Visual perception of capital letters. The Scandinavian Journal of Psycholooy, $7,(3), 189-$ 196 .

Mackinnon, D. P., O'Reilly, K. E., \& Geiselman, R. E. (1990). Improving eyewitness recall for license plates. Applied Cognitive Psychology, 4, 129-140.

Macworth, J.F. (1963). The duration of the visual image. Canadian Journal of Psychology, 17, 62-71.

Matlin, M. W. (1988). Sensation and perception. Boston: Allyn \& Bacon.

Matlin, M. W. (1989). Coonition. New York: Holt, Rinehart, \& Winston.

McIntyre, C., Fox, R., \& Neale, J. (1970). Effects of noise similarity and redundancy on the information processed from brief visual displays. Perception and Psychophysics, 7, (6), 328-332.

Mende, L., Mackinnon, D. P., \& Geiselman, R. E. (1987). Memory for license plates as a function of exposure time. Journal of Police Science and Administration, $15,(1), \frac{68-71 .}{}$ 
Miller, L. K. (1972). Letter recognition: Effects of interitem similarity and report requirements.

Perception and Psychophysics, 11, (3), 252-256.

Mueller, C. G., \& Rudolph, M. (1970). Light and vision. New York: Time-Life.

Neisser, U. Decision time without reaction time: Experiments in visual scanning. American Journal of Psychology, 76, (3), 376-385.

Pick, A. D., \& Unze, M. G. (1979). The development of visual-motor search and the use of redundant information. Bullet in of the Psychonomic Society, $14,(3), 267-270$.

Posner, M. I., Goldsmith, R. \& Welton, K. E., Jr. (1967). Perceived distance and the classification of distorted patterns. Journal of Experimental Psychology, 73, (1), $28-38$.

R. L. Polk \& Co. (1992). Polk License Plate Guide, 1992. Detroit, MI.

Rollins, M. (1987, November 5). Using artistic license, which plate is for your buggy. The oregonian, p. D1.

Rollins, M. (1988, January 21). Silhouetted mountains, fir grace winning plate. The Oregonian, p. Al.

Schiffman, H. R. (1990). The perception of color. Sensation and perception (3rd ed.). (pp. 247-266). New York: Wiley

Smith, J. (1988, September 4). Plate sweepstakes. The oregonian, $\mathrm{pp} . \mathrm{C} 1, \mathrm{C} 2$.

Solman, R. T., May, J. G., \& Schwartz, B. D. (1981). The word superiority effect: A study using parts of letters. Journal of Experimental Psychology: Human Perception and Performance, 7, (3), 552-559.

Spiker, A., Rogers, S. P., \& Cincinelli, J. (1986). Selecting color codes for a computer-generated topographic map based on perception experiments and functional requirements. Ergonomics, 29, (11), 13131328 .

Taylor, D. A. (1977). Time course of context effects. Journal of Experimental Psychology: General, 106, (4), 404-426. 
Walley, R. E., \& Weiden, T. D. (1973). Lateral inhibition and cognitive masking: $A$ neuropsychological theory of attention. Psychological Review, 80, (4), 284-302.

Wheeler, D. D. (1970). Processes in word recognition. Cognitive Psychology, 1, (1), 59-85. 


\section{APPENDIX A}

\section{M LICENSE PLATE LETTER COLORS}

The page illustrated represents the sample card available from the 3M Company. Color copiers failed to reproduce the sample colors accurately and would have been misleading if presented. Therefore, the sample is presented to aid with requests from $3 \mathrm{M}$. 


\section{Scotchlite Roll Coat Colors Series $\mathbf{4 8 0 0}$}

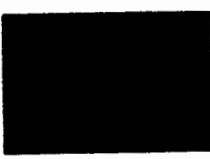

Violet 4801V

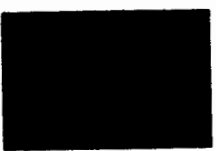

Black 4805V

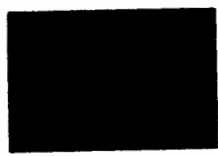

Blue Velvet $4808 \mathrm{~V}$

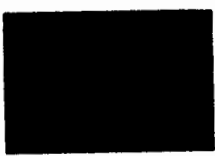

Orange 4814V

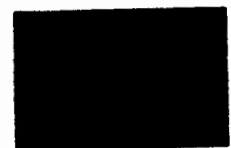

Red $4802 \mathrm{~V}$

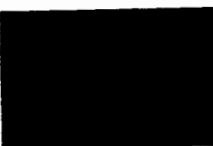

Blue 4806V

Yellow 4809V

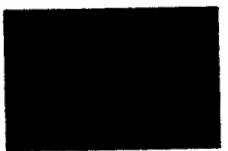

Purple 4815V

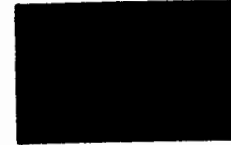

Green 4803V

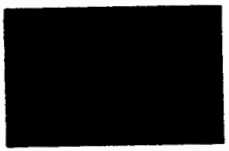

Green 4807V

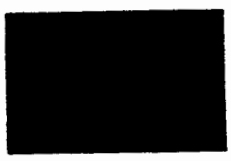

Dark Blue $4811 \mathrm{~V}$

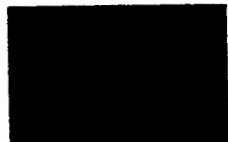

Brown 4816V

Scotenhite Roll Coat Inks Senies 4800

(Opaque) are designed tor applicatior

on Scotchite Feflective License Pla!

Sneetings

$25.0209 \cdot 0300.0$

3M Traftic Control Materials Division

3M Center Bidg. 223.3N-0

St Paul MN 55144-1000 


\section{APPENDIX B}

\section{STACK ELEMENTS}

Stack elements listed in order presented within each stack. Color code: $(B)=b l u e ;(R)=$ red $v . ;(P)=$ purple; $(B R)=$ brown . 


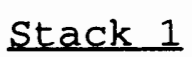

(R) FBR

(P) PAF

(BR) RTP

(B) HRL

(R) BRL

(R) EPF

(B) BTP

(R) BRP

(P) FIH

(P) $\mathrm{TBH}$

(R) PEH

(BR) ILH

(BR) ELA

(BR) RHT

(B) HTI

(P) ILP

(BR) TBI

(BR) FHP

(R) $\mathrm{AHE}$

(P) TEI

(BR) LPR

(B) IBT

(BR) $\mathrm{BPH}$

(BR) FIP

(P) TIH
Stack II

(BR) TLF

(R) IEB

(BR) LFB

(P) BRL

(R) IFL

(R) HRL

(B) FIP

(P) $\mathrm{ALH}$

(P) HTI

(R) LPR

(P) BIA

(B) ILP

(R) RTP

(R) FIH

(R) IBH

(B) BRP

(B) FBR

(P) EFP

(P) FTB

(R) $\mathrm{TBH}$

(BR) AFP

(BR) $\mathrm{REH}$

(B) $\mathrm{PEH}$

(BR) PRB

(B) RHT
Stack III

(P) BRP

(P) $\mathrm{PEH}$

(R) TBI

(B) RTP

(B) AFP

(B) TEI

(B) EFP

(BR) FBR

(P) IEB

(P) EAI

(BR) EPF

(P) BTP

(BR) ILP

(B) FIH

(P) IPB

(B) PRB

(B) $\mathrm{ALH}$

(P) RHT

(R) TIH

(B) EAL

(R) FTB

(R) PAF

(BR) $\mathrm{LAH}$

(P) FIP

(BR) BRL
Stack IV

(R) TEI

(B) $\mathrm{TIH}$

(B) BRL

(R) $\mathrm{REH}$

(P) RTP

(R) EAL

(BR) IEH

(R) EAI

(R) FTL

(R) FIP

(R) BTP

(B) IEB

(P) $\mathrm{BPH}$

(B) $\mathrm{BHF}$

(B) IPB

(B) IFL

(BR) TBH

(R) $\mathrm{ALH}$

(P) ELA

(B) ILH

(P) EPF

(P) FHP

(BR) HTI

(B) AFR

(B) EPL 


\begin{tabular}{|c|c|c|c|c|c|c|}
\hline (R) & EPL & $(\mathrm{P})$ & BHF & $(B R) \quad A F R$ & $(\mathrm{P})$ & RIA \\
\hline (B) & FTB & (B) & PAF & (R) IBT & (B) & AHE \\
\hline$(R)$ & AFP & $(B R)$ & TEI & (R) ARH & (B) & LFB \\
\hline$(P)$ & $\mathrm{LAH}$ & (B) & EPF & (R) ILH & $(\mathrm{P})$ & TBI \\
\hline (BR) & ALH & (BR) & IPB & (B) ELA & (B) & TLF \\
\hline$(\mathrm{R})$ & RIA & $(\mathrm{P})$ & EAL & (P) REH & $(R)$ & FAI \\
\hline (BR) & IEB & $(R)$ & $\mathrm{BPH}$ & (R) TLF & (P) & FBR \\
\hline (BR) & FTL & (B) & FAI & (R) FHE & (B) & LPR \\
\hline (P) & TLF & $(R)$ & $\mathrm{LAH}$ & (P) LPR & (BR) & ARH \\
\hline$(R)$ & IEH & $(\mathrm{P})$ & IEH & (B) IEH & $(B R)$ & $\mathrm{FTB}$ \\
\hline (BR) & FHE & (B) & RIA & (BR) AHE & $(B R)$ & $\mathrm{BRP}$ \\
\hline & IPB & $(R)$ & FHP & (B) IBH & $(R)$ & ILP \\
\hline$(P)$ & LFB & $(\mathrm{R})$ & AFR & $(B R) \quad B H F$ & (BR) & $\mathrm{PEH}$ \\
\hline$(\mathrm{P})$ & IFL & (B) & ARH & (BR) IFL & $(B R)$ & $B I A$ \\
\hline & PRB & $(B R)$ & TIH & $(B R) \quad R I A$ & ( $B R$ ) & IBT \\
\hline$(\mathrm{P})$ & ARH & $(B R)$ & EAI & (R) HTI & $(P)$ & AFP \\
\hline (BR) & EAL & (B) & TBI & (R) $B I A$ & (B) & FHE \\
\hline (B) & $B I A$ & $(\mathrm{P})$ & ILH & $(\mathrm{BL}) \quad \mathrm{BPH}$ & $(R)$ & EFP \\
\hline (P) 1 & FAI & $(P)$ & FHE & $(B R)$ FAI & $(R)$ & RHT \\
\hline (P) & IBH & (BR) & BTP & (B) FTL & (BR) & PAF \\
\hline (B) & $\mathrm{REH}$ & $(P)$ & IBT & (B) $\mathrm{TBH}$ & $(P)$ & PRB \\
\hline (R) & BHF & $(\mathrm{P})$ & FTL & (R) LFB & (P) & HRL \\
\hline (B) & $E A I$ & $(P)$ & EPL & (BR) HRL & (BR) & IBH \\
\hline (BR) & EFP & $(R)$ & ELA & (B) FHP & (B) & $\mathrm{LAH}$ \\
\hline$(\mathrm{P})$ & AFR & $(\mathrm{P})$ & AHE & $(B R) \quad E P L$ & (BR) & $\mathrm{FIH}$ \\
\hline
\end{tabular}


APPENDIX C

INFORMED CONSENT 
INEORMED CONSENT

I. hereby

agree to serve as a subject in the research project of "The effects of color on character recognition: An applied study of the Oregon license plate."

I understand that the study involves being seated before a presentation podium and shown various license plates. I will be asked to dictate what characters I see. I will also be presented with a series of license plates and will be asked to state which plates I like best.

I understand that the my participation will take 25-30 minutes.

It has been explained to me that the purpose of the study is to investigate new colors on the oregon license plate that will make it more readable and still aesthetically appealing.

I may not receive any direct benefit from my participation in this study, but my participation may help to increase knowledge which may benefit others in the future.

Frank Dennis has offered to answer any questions I may have about the study and what is required of me in the study. I have been assured that all information I give will be kept confidential and that the identity of all subjects will remain anonymous.

I understand that I am free to withdraw from participation in this study at any time without jeopardizing my course grade, or my relationship, with Portland State University.

I have read and understand the foregoing information and agree to participate in this study.

Date: Signature:

(If you experience problems that are the result of your participation in this study, Please contact the chair of the Human Subjects Research Review Committee, office of Grants and Contracts, 345 Cramer Hall, Portland State University, 725-3417.) 
APPENDIX D

STACK PRESENTATION ORDERS 


\begin{tabular}{|c|c|c|}
\hline Subject & Order & \\
\hline 1 & III, I, II, IV & \\
\hline 2 & $I I, I, I I I, I V$ & (data lost \\
\hline 3 & $I V, I I I, I, I I$ & (data lost \\
\hline 4 & $I I, I I I, I, I V$ & \\
\hline 5 & $I I, I, I V, I I I$ & \\
\hline 6 & $I V, I I, I I I, I$ & \\
\hline 7 & $I, I I I, I I, I V$ & \\
\hline 8 & $I I, I I I, I V, I$ & \\
\hline 9 & $I V, I, I I I, I I$ & \\
\hline 10 & $I I, I, I V, I I I$ & \\
\hline 11 & $I I, I, I V, I I I$ & \\
\hline 12 & $I, I I, I I I, I V$ & \\
\hline 13 & $I I, I, I V, I I I$ & \\
\hline 14 & $I, I I I, I I, I V$ & \\
\hline 15 & $I I, I I I, I, I V$ & \\
\hline 16 & $I I I, I, I I, I V$ & \\
\hline 17 & $I V, I I I, I I, I$ & \\
\hline 18 & $I I, I, I I I, I V$ & \\
\hline 19 & $I I I, I I, I V, I$ & \\
\hline 20 & $I I I, I V, I I, I$ & \\
\hline 21 & $I I, I I I, I, I V$ & \\
\hline 22 & $I I, I I I, I, I V$ & \\
\hline 23 & $I, I I I, I V, I I$ & \\
\hline 24 & $I V, I, I I, I I I$ & \\
\hline 25 & $I I, I I I, I V, I$ & \\
\hline
\end{tabular}




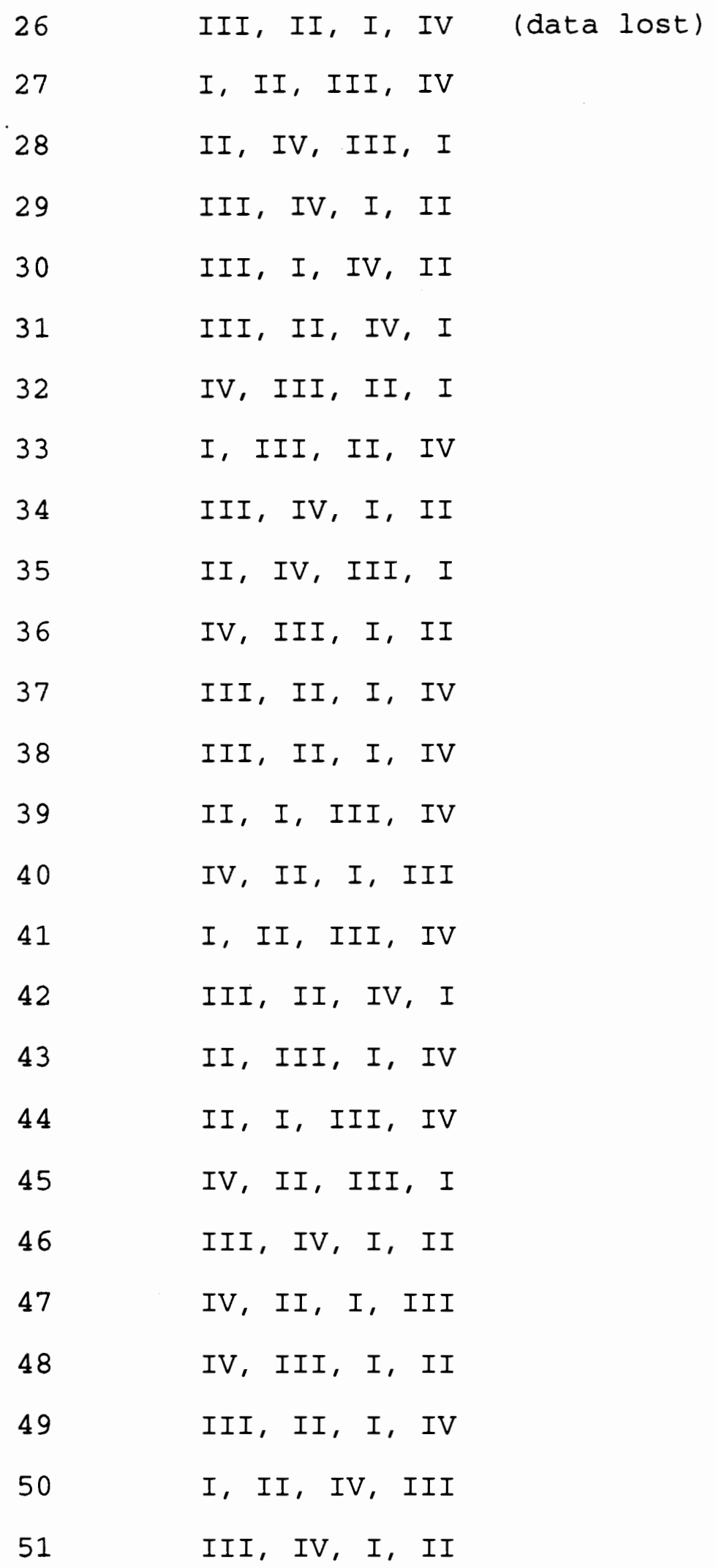


52

I, IV, III, II (data lost)

53

$I, I V, I I, I I I$

54

$I I, I, I I I, I V$ 